(1)

\title{
Anti-inflammatory effects of exercise training in adipose tissue do not require FGF21
}

\author{
Jay W Porter1, Joe L Rowles III1,2, Justin A Fletcher1,3,4, Terese M Zidon', \\ Nathan C Winn', Leighton T McCabe1, Young-Min Park1,5, James W Perfield II6, \\ John P Thyfault 7,8, R Scott Rector1,3, Jaume Padilla1,9,10 and Victoria J Vieira-Potter ${ }^{1}$ \\ 1Department of Nutrition and Exercise Physiology, University of Missouri, Columbia, Missouri, USA \\ ${ }^{2}$ Division of Nutritional Sciences, University of Illinois at Urbana-Champaign, Urbana, Illinois, USA \\ ${ }^{3}$ Research Service-Harry S Truman Memorial VA Hospital, Columbia, Missouri, USA \\ 4University of Texas Southwestern Medical Center, Dallas, Texas, USA \\ 5University of Colorado Denver - Anschutz Medical Campus, Denver, Colorado, USA \\ ${ }^{6}$ Lilly Research Laboratories, Indianapolis, Indiana, USA \\ 7Department of Molecular and Integrative Physiology, University of Kansas Medical Center, Kansas City, Kansas, USA \\ ${ }^{8}$ Kansas City VA Medical Center, Kansas City, Missouri, USA \\ ${ }^{9}$ Department of Child Health, University of Missouri, Columbia, Missouri, USA \\ ${ }^{10}$ Dalton Cardiovascular Research Center, University of Missouri, Columbia, Missouri, USA
}

Correspondence should be addressed to $V$ J Vieira-Potter Email vieirapotterv@missouri.edu

\begin{abstract}
Exercise enhances insulin sensitivity; it also improves adipocyte metabolism and reduces adipose tissue inflammation through poorly defined mechanisms. Fibroblast growth factor 21 (FGF21) is a pleiotropic hormone-like protein whose insulin-sensitizing properties are predominantly mediated via receptor signaling in adipose tissue (AT). Recently, FGF21 has also been demonstrated to have anti-inflammatory properties. Meanwhile, an association between exercise and increased circulating FGF21 levels has been reported in some, but not all studies. Thus, the role that FGF21 plays in mediating the positive metabolic effects of exercise in AT are unclear. In this study, FGF21-knockout (KO) mice were used to directly assess the role of FGF21 in mediating the metabolic and anti-inflammatory effects of exercise on white AT (WAT) and brown AT (BAT). Male FGF21KO and wild-type mice were provided running wheels or remained sedentary for 8 weeks ( $n=9-15 /$ group) and compared for adiposity, insulin sensitivity (i.e., HOMA-IR, Adipo-IR) and AT inflammation and metabolic function (e.g., mitochondrial enzyme activity, subunit content). Adiposity and Adipo-IR were increased in FGF21KO mice and decreased by EX. The BAT of FGF21KO animals had reduced mitochondrial content and decreased relative mass, both normalized by EX. WAT and BAT inflammation was elevated in FGF21KO mice, reduced in both genotypes by EX. EX increased WAT Pgc1alpha gene expression, citrate synthase activity, COX I content and total AMPK content in WT but not FGF21KO mice. Collectively, these findings reveal a previously unappreciated anti-inflammatory role for FGF21 in WAT and BAT, but do not support that FGF21 is necessary for EX-mediated anti-inflammatory effects.
\end{abstract}

\author{
Key Words \\ $\checkmark$ exercise \\ - inflammation \\ - FGF21 \\ - adipose tissue
}




\section{Introduction}

Two major types of adipose tissue (AT) exist: white (WAT), primarily serving as the body's major energy storage site and brown (BAT), which predominately converts energy into heat through uncoupled respiration. AT is an active endocrine organ that is profoundly affected by exercise. Exercise lessens WAT inflammation and improves systemic metabolic health, even in the settings of obesity (Vieira et al. 2009a, Welly et al. 2016), although the mechanisms are not fully understood. Less is known about the effect of exercise on BAT inflammation. In this regard, we recently showed that exercise training also reduces obesity-induced BAT inflammation in rodents (Wainright et al. 2015, Welly et al. 2016). In addition, evidence suggests that exercise increases WAT mitochondrial content and function (Stallknecht et al. 1991, Lee et al. 2014, Wainright et al. 2015, Stanford \& Goodyear 2016), which is associated with metabolically healthier WAT. Accordingly, the exercise-induced changes in WAT (and possibly BAT) mitochondria may contribute to some of the metabolic benefits of exercise (Stanford et al. 2015). Yet, the specific mechanisms by which exercise reduces inflammation and induces mitochondrial adaptations are not completely understood.

Fibroblast growth factor 21 (FGF21), a pleotropic endocrine hormone produced by several tissues, plays an important role in systemic glucose and lipid metabolism (Kharitonenkov et al. 2005, Zhang et al. 2008, Iglesias et al. 2012, Kim \& Lee 2014, Samms et al. 2015). FGF21 enhances adipocyte glucose uptake and improves insulin resistance and diabetes (Kharitonenkov et al. 2005, Kharitonenkov \& Shanafelt 2008, Kim \& Lee 2014, Samms et al. 2015). Importantly, it exerts the majority of its systemic beneficial effects via its actions in AT. Indeed, in the absence of intact receptor signaling in AT, the majority of FGF21's metabolic effects are nullified (Adams et al. 2012). FGF21 reduces WAT mass and enhances energy expenditure by activating BAT. Similar benefits have been shown with exercise training (Kim et al. 2013, Kim \& Lee 2014, Ji et al. 2015), which has been shown to increase FGF21 secretion in some human and rodent studies (Kim et al. 2013, Loyd et al. 2016, Tanimura et al. 2016). Recently, anti-inflammatory properties of FGF21 have been reported (Feingold et al. 2012, Singhal et al. 2016, Yu et al. 2016); however, whether exercise-induced anti-inflammatory actions in AT are mediated via FGF21 has not been addressed.
The purpose of the current investigation was to determine the role that FGF21 plays in exercise trainingmediated metabolic adaptations in WAT and BAT. We and others have consistently observed robust antiinflammatory effects of exercise in AT (Vieira et al. 2009a,b, Castellani et al. 2014, Welly et al. 2016), but the mechanisms underlying this observation are not well understood. Here, we tested the hypothesis that lack of FGF21 leads to a dysfunctional AT phenotype. Further, we determined if FGF21 is necessary for the antiinflammatory effects of exercise training in WAT and BAT using a mouse model of FGF21 ablation.

\section{Materials and methods}

\section{Animal protocol}

The animal protocol was approved by the Institutional Animal Care and Use Committee at the University of Missouri-Columbia and Harry S. Truman Memorial VA Hospital. Male FGF21-knockout mice on a C57BL/6NTac background (FGF21KO) and age matched, but not littermate, C57BL/6NTac WT mice controls were bred by Taconic Biosciences (Hudson, NY) and kindly provided by Eli Lilly (Indianapolis, IN). FGF21 mice were generated by backcrossing with C57BL/ 6 mice for $>15$ generations. Prior experiments and experience with this model determined that WT littermates and age-matched C57BL/6 animals were phenotypically indistinguishable. FGF21KO and WT mice (11-12 weeks of age) were provided a running wheel for 8 weeks and designated as FGF21KO-EX $(n=14)$ and WT-EX $(n=15)$. Separate groups of mice remained sedentary without access to running wheels and were designated FGF21KO-SED $(n=9)$ and WT-SED $(n=10)$. All mice were individually housed in temperature controlled animal quarters $\left(21^{\circ} \mathrm{C}\right)$ with a 06:00-18:00 light and 18:00-06:00 dark cycle. All groups were provided ad libitum standard rodent chow (Formulab 5008; Purina Mills, Brentwood, MO). Running wheel revolutions were monitored and counted continuously using a Sigma BC 509 bike computer (St. Charles, IL). Running distance was obtained daily between 08:00 and 10:00. Body mass and food consumption were measured on the same day each week throughout the study.

After the 8-week intervention, running wheels were locked for $24 \mathrm{~h}$ and mice were fasted for $5 \mathrm{~h}$, anesthetized with pentobarbital sodium $(100 \mathrm{mg} / \mathrm{kg})$ and then exsanguinated by removal of the heart. Blood was

Published by Bioscientifica Ltd. 
collected via cardiac puncture within $10 \mathrm{~min}$ of mice being anesthetized (pentobarbital).

\section{Body composition}

Fat and lean mass were measured using an EchoMRI 4in1-1100 analyzer (EchoMRI; Houston, TX). Visceral WAT (epididymal), subcutaneous WAT (inguinal region) and BAT (interscapular region) fat pads were removed, weighed and fixed in formalin or flash-frozen in liquid nitrogen until further analysis.

\section{RNA isolation, q-PCR}

BAT and WAT (from visceral and subcutaneous regions) samples were homogenized in TRIzol solution using a tissue homogenizer (TissueLyser LT, Qiagen, Valencia, CA). Total RNA was isolated according to the Qiagen's RNeasy lipid tissue protocol and analyzed using a Nanodrop spectrophotometer (Thermo Scientific) to assess purity and concentration. First-strand cDNA was synthesized from total RNA using the High-Capacity cDNA Reverse Transcription kit (Applied Biosystems). Quantitative realtime PCR was performed as previously described (Padilla et al. 2013, Crissey et al. 2014) using the ABI StepOne Plus sequence detection system (Applied Biosystems). Primer sequences were designed using NCBI Primer Design tool and purchased from IDT (Coralville, IA). Gapdh and $18 \mathrm{~s}$ were used as housekeeping control genes and mRNA expression values are presented relative to the WT-SED group. Forward and reverse primer sequences are provided in Table 1.

\section{Fasting blood parameters}

Circulating fasting plasma levels of glucose, lipids, FGF21 and adiponectin were assessed as previously described and reported (Fletcher et al. 2016); those data are also included in Table 2 because of their relevance to the new AT data reported herein. Homeostatic model assessment of insulin resistance (HOMA-IR) (Matthews et al. 1985) and AT insulin resistance (Adipo-IR), calculated as fasting NEFA $\times$ fasting insulin (Lomonaco et al. 2012), were used to assess insulin resistance.

\section{Western blotting}

Triton X-100 tissue lysates were used to produce Western blot-ready Laemmli samples. Protein samples $(10 \mu \mathrm{g} / \mathrm{lane})$ were separated by SDS-PAGE, transferred to polyvinylidene difluoride membranes and probed with primary antibodies: oxidative phosphorylation (OxPhos) complexes I through $\mathrm{V}$ of the electron transport chain (ETC) (1:2000, MitoProfile Total OxPhos Rodent WB Antibody Cocktail, MitoSciences; Eugene, OR), 5'AMP-activated protein kinase (AMPK) (1:1000) and phospho-AMPK at Threonine 172 and Serine 485 residues (1:1000, Cell Signaling), protein kinase B (1:500, Cell Signaling), phosphorylation at Serine 473 (1:250, Cell Signaling), GLUT4 (1:1000, Cell Signaling) and

Table 1 qPCR primer sequences.

\begin{tabular}{l} 
Primer name \\
\hline $18 s$ \\
Gapdh \\
Fgf21 \\
Tnga \\
II6 \\
Leptin \\
Mcp-1 \\
Cd11c \\
Cd8 \\
Erm-1 \\
Ifngamma \\
P22phox \\
Ddit3 \\
Ucp-1 \\
PrdM16 \\
Pgc1a \\
Cidea \\
Lpl \\
Irs-1
\end{tabular}

\begin{tabular}{l} 
Forward sequence \\
\hline TCA AGA ACG AAA GTC GGA GG \\
CCA GCT ACT CGC GGC TTT A \\
GTA CCTT CTA CAC AGA TGA CGA A \\
CTA TGT CTC AGC CTC TTC TC \\
TCC AGT TGC CTT CTT GGG AC \\
CCT ATT GAT GGG TCT GCC CG \\
GCT ATC ATC TTT CAC ACG AAG \\
ATG CCA CTG TCT GGC TTC AT \\
CTA GAC GTG GAG GAA GAC GC \\
CGG TAT CAT GAG TTG ATG GCA GT \\
AGC AAG GCG AAA AAG GAT GC \\
ACT CTA TCG CTG CAG GTG TG \\
ATG TTG AAG ATG AGC GGG TG \\
CAC GGG GAC CTA CAA TGC TT \\
CAG CAC GGT GAA GCC ATT C \\
CCC TGC CAT TGT TAA GAC C \\
TGC TCT TCT GTA TCG CCC AGT \\
GAG ACT CAG AAA AAG GTC ATC \\
GAT CGT CAA TAG CGT AAC TG
\end{tabular}

\begin{tabular}{l} 
Reverse sequence \\
\hline GGA CAT CTA AGG GCA TCA C \\
GAG GGC TGC AGT CCG TAT TT \\
CGC CTA CCA CTG TTC CAT CCT \\
CAT TTG GGA AAC TTC TCA TCC \\
AGT CTC CTC TCC GGA CTT GT \\
TGA GCG CTA CCT GCA TAG AC \\
CAT CTT CTT GAC TCT TAG GC \\
GAG CCA GGT CAA AGG TGA CA \\
GAG GAC CAT GGG TGA CTC TT \\
CCT TGG TGC ATG AAA CTC CT \\
TCA TTG AAT GCT TGG CGC TG \\
AAG CTT CAC CAC AGA GGT CAG \\
TGG AAC ACT CTC TCC TCA GGT \\
ACA GTA AAT GGC AGG GGA CG \\
GCG TGC ATC CGC TTG TG \\
TGC GC TGT TCC TGC TTT C \\
GCC GTG TTA AGG AAT CTG CTG \\
GTC TTC AAA GAA CTC AGA TGC \\
ATC GTA CCA TCT ACT GAA GAG
\end{tabular}


Table 2 Serum values.

\begin{tabular}{|c|c|c|}
\hline Variable & WT-SED & WT-EX \\
\hline $\mathrm{FGF} 21, \mathrm{pg} / \mathrm{mL}$ & $892.5 \pm 199.63$ & $858.6 \pm 130.97$ \\
\hline Insulin, ng/mL & $1.23 \pm 0.10$ & $0.82 \pm 0.08^{\dagger}$ \\
\hline Glucose, $\mathrm{mg} / \mathrm{dL}$ & $280.2 \pm 10.75$ & $280.53 \pm 15.77$ \\
\hline Adiponectin, $\mu \mathrm{g} / \mathrm{mL}$ & $21.38 \pm 1.05$ & $18.10 \pm 0.64^{\dagger}$ \\
\hline $\mathrm{TG}, \mathrm{mg} / \mathrm{dL}$ & $61.06 \pm 4.69$ & $47.33 \pm 2.10^{\dagger}$ \\
\hline Cholesterol, mg/dL & $95.37 \pm 4.96$ & $91.42 \pm 1.90$ \\
\hline FFA, $\mu \mathrm{M}$ & $769.44 \pm 53.55$ & $598.89 \pm 32.73^{\dagger}$ \\
\hline
\end{tabular}

\begin{tabular}{c}
\hline FGF21KO-SED \\
\hline BDL \\
$2.61 \pm 0.29^{*}$ \\
$332.22 \pm 21.89^{*}$ \\
$20.17 \pm 0.92$ \\
$64.44 \pm 3.91$ \\
$111.51 \pm 4.28^{*}$ \\
$813.11 \pm 26.14$ \\
\hline
\end{tabular}

\begin{tabular}{c}
\hline FGF21KO-EX \\
\hline BDL \\
$1.95 \pm 0.23^{* \dagger}$ \\
$350.84 \pm 13.21^{*}$ \\
$17.85 \pm 0.49^{\dagger}$ \\
$57.89 \pm 2.53^{\dagger}$ \\
$99.10 \pm 4.28^{*}$ \\
$680.22 \pm 35.05^{\dagger}$ \\
\hline
\end{tabular}

*Significant genotype main effect $(P \leq 0.05)$; ${ }^{+}$Significant exercise main effect $(P \leq 0.05)$.

beta-actin (1:2000, Cell Signaling). Intensity of individual protein bands was quantified using FluoroChem HD2 (AlphaView, version 3.4.0.0) and were expressed as a ratio to housekeeping band, beta-actin.

\section{Histology}

Formalin-fixed visceral WAT and BAT samples were processed through paraffin embedment, sectioned at $5 \mu \mathrm{m}$ and stained with hematoxylin and eosin (i.e., H\&E) for morphometric determinations, as previously described (Padilla et al. 2013). Sections were evaluated using an Olympus BX60 photomicroscope (Olympus, Melville, $\mathrm{NY}$ ) and photographs were taken at $20 \times$ magnification via Spot Insight digital camera (Diagnostic Instruments, Inc., Sterling Heights, MI). Adipocyte size was calculated based on 100 adipocytes/animal obtained from three $20 \times$ fields per animal. Briefly, cross-sectional areas of the adipocytes were obtained from perimeter tracings using ImageJ software as performed previously (Wainright et al. 2015). All procedures were performed by an investigator who was blinded to the experimental conditions.

\section{Statistics}

Two-way analysis of variance was performed using SPSS, v21 to assess differences among groups for genotype and exercise main effects, as well as genotypexexercise interactions. Post hoc Tukey comparison was utilized to assess between-group differences if genotype by exercise interactions showed statistical significance. For such post hoc analyses, between-group differences are indicated by ' $a$ ' when different from all other groups, ' $b$ ' when different compared to WT-SED and ' $\mathrm{c}$ ' when different compared to FGF21KO-EX. All data are presented as means \pm standard error of the mean (s.E.); $P \leq 0.05$ was considered statistically significant.

\section{Results}

\section{Genotype and exercise impact plasma metabolite profile}

As previously reported (Fletcher et al. 2016), no differences existed in running distance between FGF21KO-EX and WT-EX groups, and both groups experienced an increase in energy intake and relative cardiac tissue mass, suggestive of similar training adaptations. However, compared to WT-EX, FGF21KO-EX animals weighed more, had a higher total body fat percentage and consumed more total energy (Table 3). As shown in Table 2, FGF21KO animals also had greater fasting serum levels of total cholesterol, glucose and insulin; whereas no genotype differences were observed for triglycerides (TG), NEFAs or the insulinsensitizing adipokine, adiponectin. In both genotypes,

Table 3 Animal characteristics.

\begin{tabular}{l} 
Variable \\
\hline Body weight, $\mathrm{g}$ \\
Running distance, $\mathrm{km} /$ day \\
Fat mass, $\mathrm{g}$ \\
Lean mass, $\mathrm{g}$ \\
Percent body fat, \% \\
Food consumption, g/week \\
Feeding efficiency
\end{tabular}

\begin{tabular}{c}
\hline WT-SED \\
\hline $29.3 \pm 1.2$ \\
NA \\
$5.3 \pm 0.9$ \\
$22.9 \pm 0.6$ \\
$17 \pm 2$ \\
$25.8 \pm 0.2$ \\
$0.024 \pm 0.0004$
\end{tabular}

\begin{tabular}{c}
\hline WT-EX \\
\hline $26.9 \pm 0.5^{\dagger \S}$ \\
$7.75 \pm 0.60$ \\
$2.7 \pm 0.4^{\dagger \S}$ \\
$22.9 \pm 0.3$ \\
$10 \pm 1^{\dagger}$ \\
$32.3 \pm 0.7^{\dagger}$ \\
$0.006 \pm 0.002^{\dagger}$ \\
\hline
\end{tabular}

\begin{tabular}{c}
\hline FGF21KO-SED \\
\hline $37.4 \pm 0.8 * \S$ \\
NA \\
$10.8 \pm 0.4 * \S$ \\
$25.9 \pm 0.4^{*}$ \\
$29 \pm 1^{*}$ \\
$28.6 \pm 0.2 *$ \\
$0.033 \pm 0.003$
\end{tabular}

\begin{tabular}{c} 
FGFK21KO-EX \\
\hline $31.6 \pm 0.8^{* \dagger}$ \\
$6.96 \pm 0.73$ \\
$5.6 \pm 0.6^{* \dagger}$ \\
$25.1 \pm 0.4^{* \dagger}$ \\
$17 \pm 1^{* \dagger}$ \\
$33.7 \pm 0.8^{* \dagger}$ \\
$0.009 \pm 0.003^{\dagger}$
\end{tabular}

*Significant genotype main effect $(P \leq 0.05)$; ${ }^{+}$Significant exercise main effect $(P \leq 0.05)$. 
EX reduced TG, NEFA and adiponectin levels. No FGF21 protein was detected in serum of FGF21KO mice and EX did not affect circulating levels of FGF21 in WT mice.

\section{Exercise improves adipose tissue insulin sensitivity in FGF21KO mice}

Based on HOMA-IR values, FGF21KO mice were significantly more insulin-resistant than WT controls (Fig. 1A) and EX had a tendency $(P=0.112)$ to improve HOMA-IR in both genotypes. Similarly, FGF21KO mice had significantly greater Adipo-IR (a surrogate index of AT insulin resistance (Lomonaco et al. 2012)), and EX significantly reduced Adipo-IR for both genotypes (Fig. 1B). Additionally, EX increased epididymal WAT insulin receptor substrate 1 (Irs1) expression (Fig. 1C). However, gene expression of the enzyme necessary for insulin-mediated lipid uptake into AT, lipoprotein lipase ( $L p l)$, was not significantly altered (Fig. 1C).
Phosphorylated (i.e., activated form of) AKT content was significantly upregulated in visceral WAT in the FGF21KO mice (Fig. 1D); whereas GLUT4 protein content was significantly elevated in all three FGF21KO mice groups compared to WT (Fig. 1E). Neither of those proteins were significantly affected by EX in any of the three depots.

In concordance with greater total adiposity, FGF21KO mice had significantly greater visceral and subcutaneous WAT depot weights compared to WT mice, while exercise decreased weights to similar values as WT-SED, but not to the extent of WT-EX (Fig. 2A and $B)$. The significant genotype $\times \mathrm{EX}$ interaction for both subcutaneous and visceral WAT depots is indicative of a more robust adiposity-reducing effect of EX in the FGF21KO animals. Morphometric analysis of histologic sections from the visceral WAT depot revealed mean adipocyte size was greater for the FGF21KO compared to WT mice and was reduced with EX in both genotypes (Fig. 2C and D).
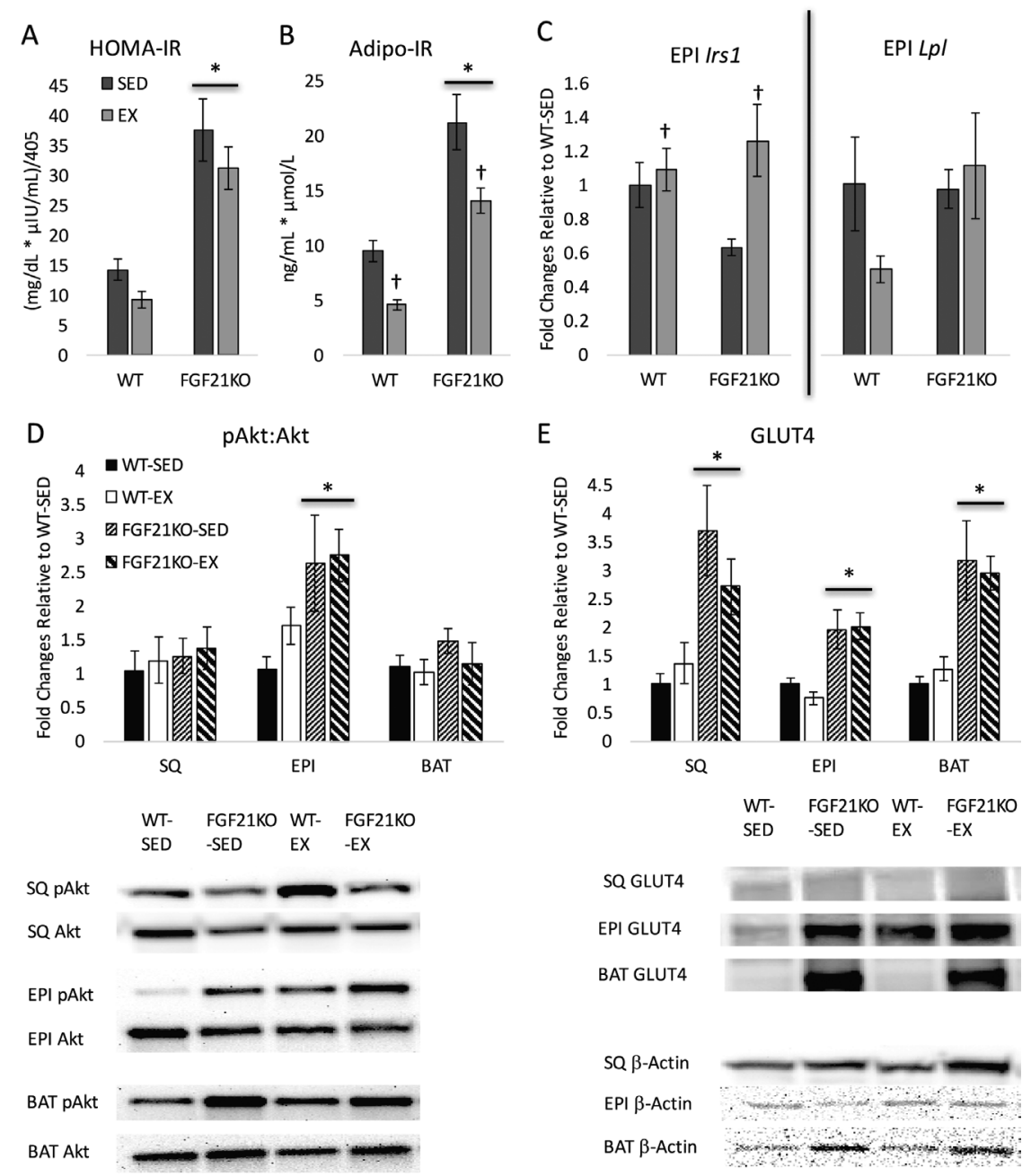

Figure 1

Influence of FGF21 ablation and/or exercise on insulin resistance and WAT. (A) Homeostasis model assessment of insulin resistance (HOMA-IR), (B) adipose tissue insulin resistance (Adipo-IR), (C) EPI Irs1 and EPI Lp/ gene expression, (D) phospho-AKT:AKT protein content and representative Western blots below and (E) GLUT4 protein content with representative Western blots below. EPI, epididymal (visceral); EX, exercise; FGF21KO, FGF21 knockout; SED, sedentary; SQ, subcutaneous (inguinal); WT, wild-type. Values are means \pm standard error (s.E.) $(n=9-15)$. *Significant genotype main effect $(P \leq 0.05)$; +Significant exercise main effect $(P \leq 0.05)$. http://joe.endocrinology-journals.org DOI: $10.1530 / J O E-17-0190$
() 2017 Society for Endocrinology Printed in Great Britain 
A
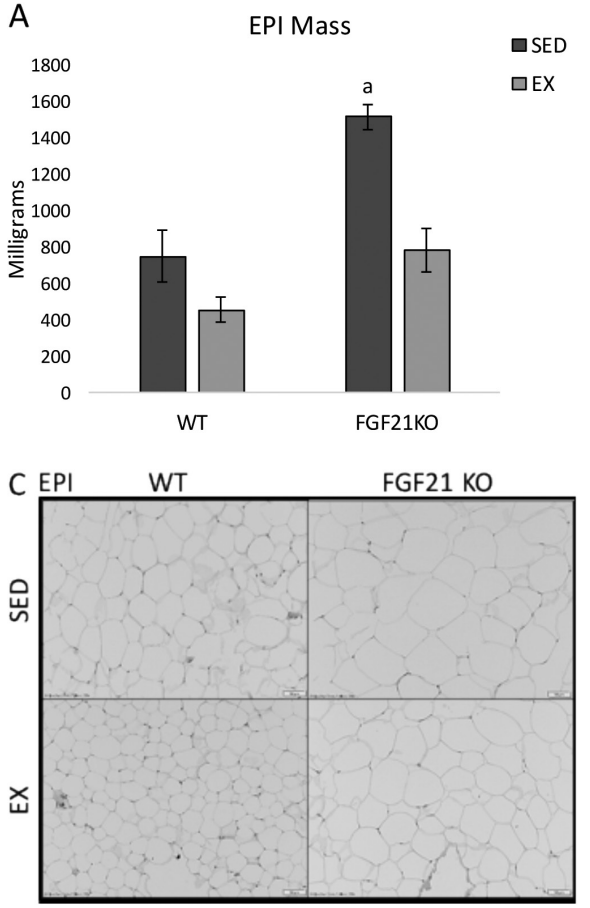

B

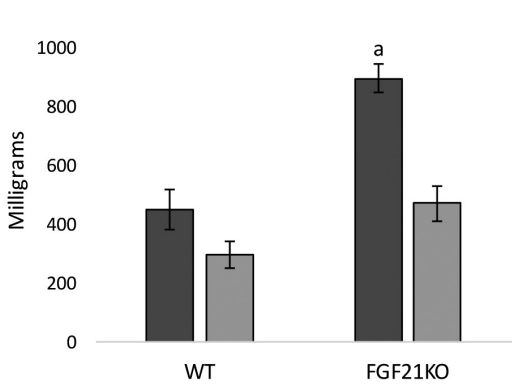

D

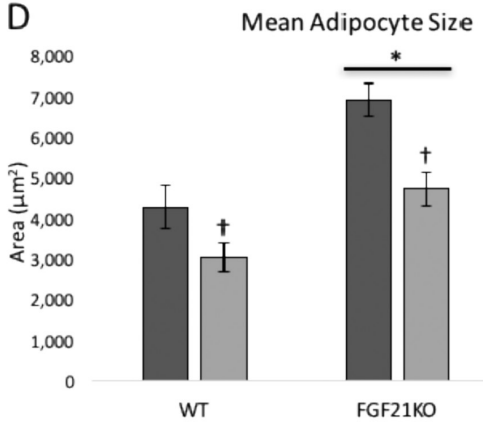

\section{Figure 2}

Influence of FGF21 ablation and/or exercise on WAT and BAT characteristics. (A) EPI mass, (B) SQ mass, (C) Representative images of EPI H\&E staining and (D) EPI mean adipocyte size. EPI, epididymal (visceral); EX, exercise; FGF21KO, FGF21 knockout; SED, sedentary; SQ, subcutaneous (inguinal); WT, wild-type. Values are means \pm standard error (s.E.). * Significant genotype main effect $(P \leq 0.05)$; tSignificant exercise main effect $(P \leq 0.05)$; asignificantly different compared to all other groups based on significant genotype $x$ exercise effect followed by post hoc Tukey's tests $(P \leq 0.05)$.

\section{WAT inflammation is increased in FGF21KO mice and exercise rescues this phenotype}

As shown in Fig. 3A and B, FGF21 mRNA was not detected in AT of KO animals (or liver; data not shown), validating the model. Corresponding with their greater adiposity, FGF21KO mice had greater leptin expression in both visceral and subcutaneous WAT. The inflammatory markers monocyte chemoattractant protein-1 (Mcp-1), tumor necrosis factor alpha (Tnfa), the marker expressed on inflammatory/M1 macrophages (Cd11c) and the T cell marker $C d 8$ were all significantly upregulated in visceral WAT of FGF21KO mice relative to WT controls. Consistent with the previously reported anti-inflammatory effects of exercise in WAT, EX reduced the inflammatory profile of both visceral and subcutaneous WAT independent of genotype (Fig. 3).
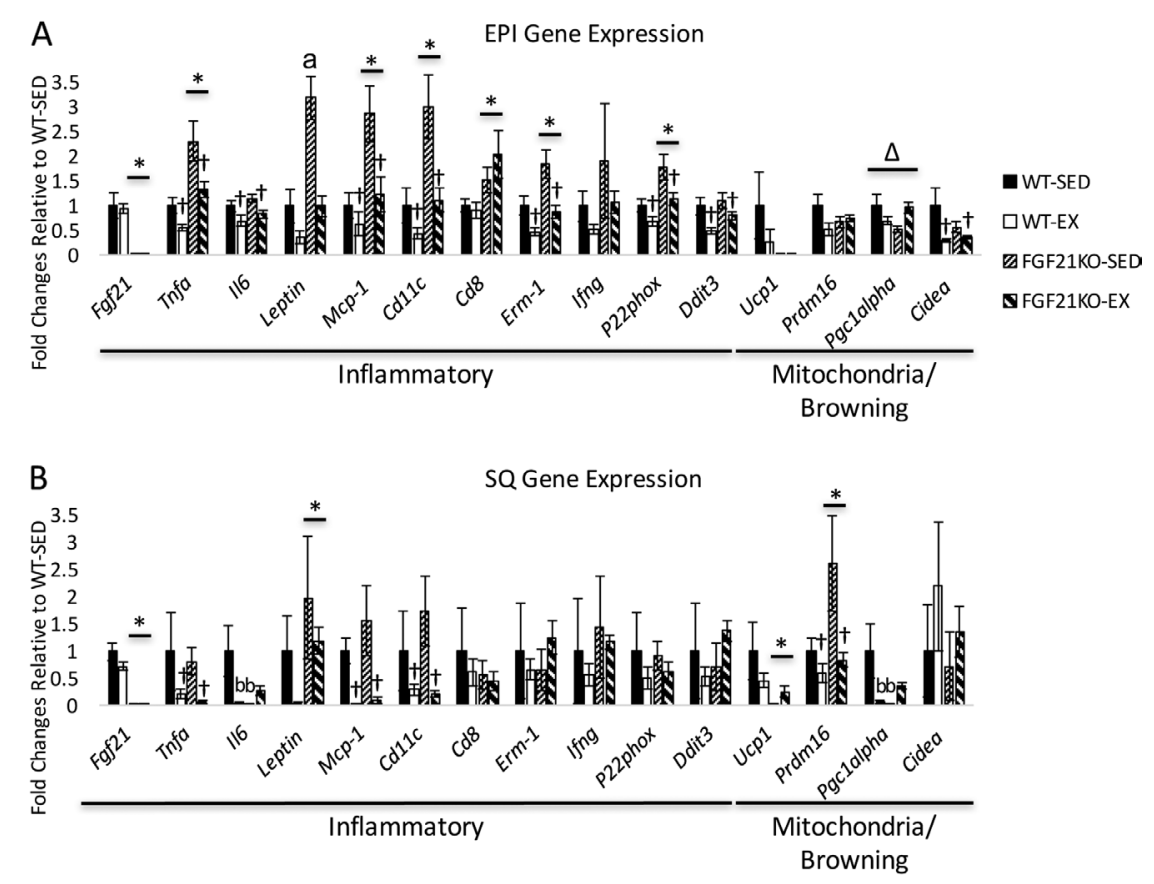

\section{Figure 3}

Influence of FGF21 ablation and/or exercise on WAT gene expression. (A) EPI gene expression, (B) SQ gene expression. EPI, epididymal (visceral); EX, exercise; FGF21KO, FGF21 knockout; SED, sedentary; SQ, subcutaneous (inguinal); $W T$, wild-type. Values are means \pm s.E. $\Delta$ Significant genotype by exercise interaction effect $(P \leq 0.05)$; *Significant genotype main effect $(P \leq 0.05)$; +Significant exercise main effect $(P \leq 0.05)$; aSignificantly different compared to all other groups based on significant genotype x exercise effect followed by post hoc Tukey's tests $(P \leq 0.05)$; bsignificantly different than WT-SED based on significant genotype $x$ exercise effect followed by post hoc Tukey's test $(P \leq 0.05)$. 


\section{Effects of FGF21 ablation and exercise on mitochondrial} characteristics of WAT

As AT mitochondrial metabolism is potentially affected by exercise, we assessed markers of mitochondrial content and function in subcutaneous and visceral WAT. Uncoupling protein 1 (Ucp1) mRNA was virtually undetectable in subcutaneous and visceral WAT of FGF21 KO mice. For Pgc1alpha, which induces mitochondrial biogenesis (Fletcher et al. 2016), a significant genotype $\times \mathrm{EX}$ interaction was observed in both WAT depots (Fig. 3). That is, in both visceral and subcutaneous WAT, FGF21KO animals had lower Pgc1alpha expression, suggesting that lack of FGF21 may reduce mitochondrial biogenesis in WAT; this effect of FGF21 ablation was partially rescued by EX. Interestingly, EX affected WT mice in the opposite way; they experienced (in both WAT depots) an EX-mediated reduction in Pgc1alpha and a similar, yet non-significant, trend with Ucp1. Similarly, Prdm16, the cell fate dictating protein previously shown to induce beige adipogenesis, was reduced with EX in subcutaneous WAT but the effect was not significant in visceral WAT (Fig. 3).

In visceral WAT, EX increased mitochondrial citrate synthase activity, but only in WT mice. In fact, EX actually reduced citrate synthase activity in FGF21KO mice (Fig. 4A). As shown in Fig. 4B, in both genotypes, EX tended to reduce ETC subunit content (COXI, $P=0.110$; COXII, $P=0.008$; COXIII, $P=0.041$; COXIV, $P=0.008$, COXV, $P=0.192)$ in visceral WAT. Similarly, in both genotypes, EX increased AMPK inhibitory activity (Fig. 4C), as indicated by increased serine phosphorylation. In subcutaneous WAT, we noted no differences between groups in citrate synthase activity (Fig. 4D); COXIV content (Fig. 4E), a validated marker of mitochondrial content (Sun et al. 2015) or AMPK content or phosphorylation status (i.e., activity) (Fig. 4F). In subcutaneous WAT, ATP synthase (i.e., COXV) content was increased in FGF21KO mice. EX increased ETC subunit COXI in WT only, and COXIII in both genotypes.

\section{FGF21-null mice display an abnormal BAT phenotype, which is restored with exercise training}

Similar to WAT depots, interscapular BAT mass was greater in FGF21KO compared to WT mice and EX reduced total interscapular BAT in both genotypes (Fig. 5A). When expressed relative to total body fat, as measured by EchoMRI, FGF21KO had lower relative BAT, assessed by the equation (BAT mass/(body mass $x$ body fat percentage) $) \times 100$, which was almost fully restored with EX (Fig. 5B). Histological analysis suggested that the increased BAT mass in FGF21KO-EX (and SED) mice was due to increased 'whitening', based on a visual increase in lipid droplet size in both FGF21KO-EX and SED mice compared to their respective controls (Fig. 5C). Since recent work revealed an important, lipoprotein lipase (LPL)-dependent role of FGF21 in accelerating lipoprotein catabolism in BAT (Schlein et al. 2016), the BAT-whitening phenotype observed in the FGF21KO caused us to question whether impaired Lpl-mediated lipoprotein catabolism may have played a role. Indeed, we found a suppression in $L p l$ gene expression in the FGF21KO compared to WT mice (Fig. 5D). EX did not significantly affect BAT LPL gene expression, with a tendency to reduce it in the FGF21KO. Consistent with the observation of increased BAT whitening, leptin, the classic adipokine that increases in WAT with adipocyte expansion, was significantly upregulated in $\mathrm{KO}$ animals, as were several inflammatory and pro-oxidant genes that are also known to increase in WAT with obesity (i.e., Mcp-1; Tnfa; Cd11c; P22phox, Fig. 5E). Remarkably, all those changes observed in FGF21KO-SED mice were completely normalized by EX, which had a similar protective effect in the WT animals. EX also reduced the classic macrophage marker, Erm-1 and the cytokine Il-6, which were not affected by FGF21 ablation. Since Tnfa, a major inflammatory cytokine, is known to cause adipocyte insulin resistance in WAT via impaired Irs 1 activity (Hotamisligil et al. 1996), we measured Irs 1 gene expression in BAT to determine if there was evidence of inflammation-induced insulin resistance or protective effects of EX in this regard. An elevation in Irs1 may be indicative of adipocyte compensation for insulin resistance; thus, reduced levels may indicate improvements in insulin signaling. Consistent with this hypothesis, EX reduced both BAT Tnfa and Irs1 expression; this EX effect was observed in both WT and KO groups (Fig. 5D). These findings validate previous work showing EX training reduces inflammation in WAT (Vieira et al. 2009a, Linden et al. 2014) and BAT (Xu et al. 2011, Welly et al. 2016) and demonstrate that while inflammation is increased in the AT of FGF21KO mice, the anti-inflammatory effects of EX do not require FGF21.

BAT mitochondrial function was assessed by measuring mitochondrial enzyme (i.e., citrate synthase) activity (Fig. 6A), ETC subunit protein content (Fig. 6B), AMPK content and phosphorylation state (Fig. 6D). Here, we found that lack of FGF21 significantly reduced the amount of two important ETC subunits, COXIII and COXIV. Similar to subcutaneous WAT, gene expression of Prdm16 was increased in BAT of FGF21-KO mice, yet

Published by Bioscientifica Ltd. 
A

EPI Citrate Synthase Activity

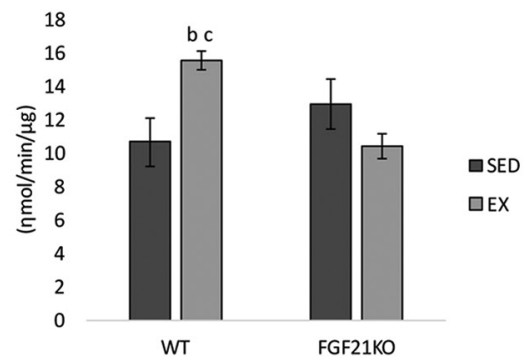

B

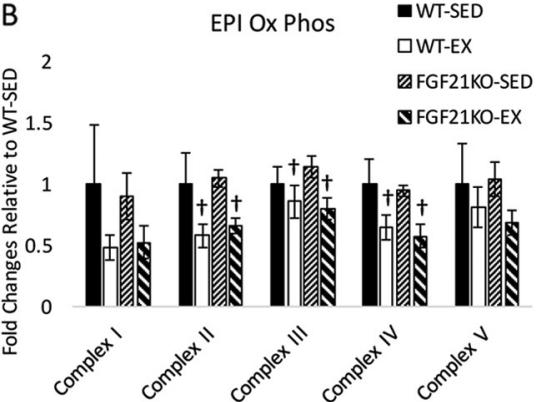

EPI OX PhOS WT- FGF21KO WT- FGF21KO Western Blots

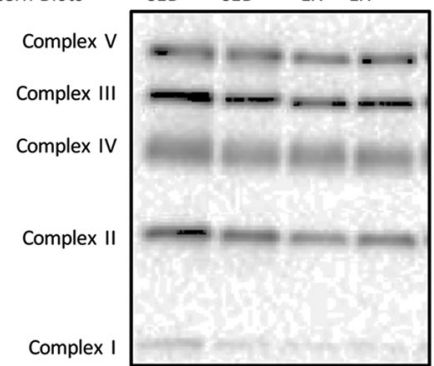

C
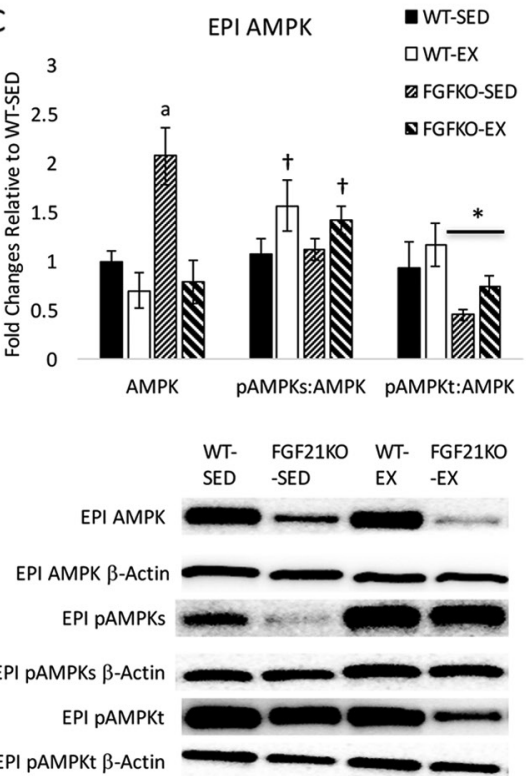

D

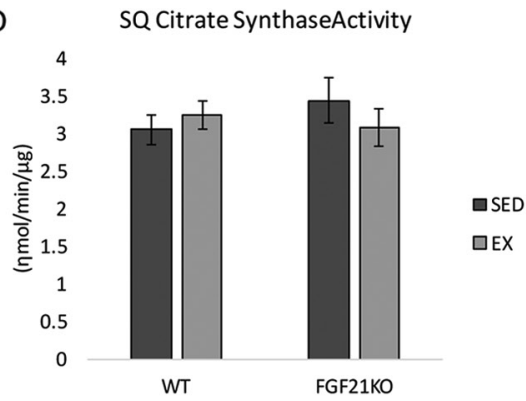

E

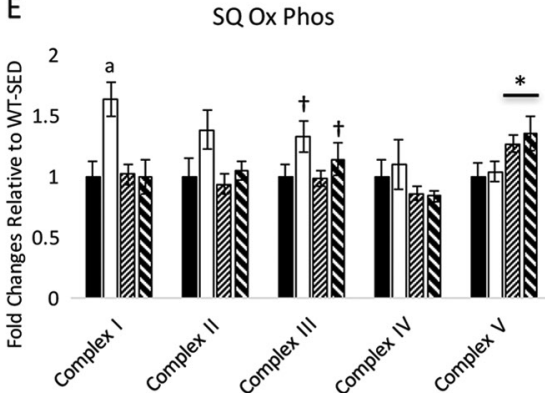

SQ OxPhos WT- FGF21KO WT- FGF21KO Western Blots SED -SED EX

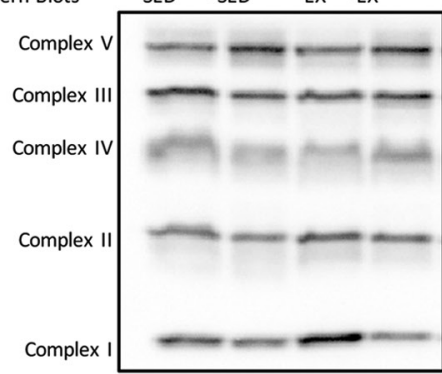

SQ AMPK

3

2.5

2

1.5

1

0.5

AMPr

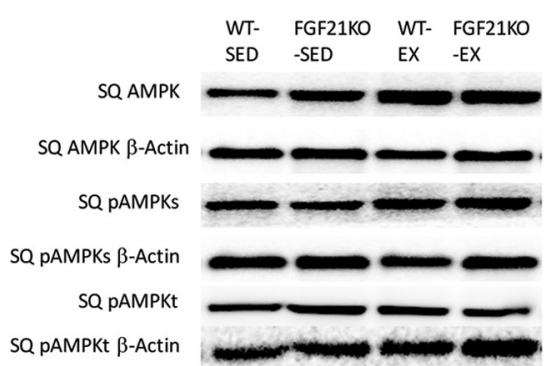

Figure 4

Influence of FGF21 ablation and/or exercise on WAT mitochondrial content and activity. (A) EPI citrate synthase activity, (B) EPI Ox Phos content with representative Western blot images, (C) EPI AMPK and phosphorylated AMPK at Serine 485 and Threonine 172 residues with representative Western blot images, (D) SQ citrate synthase activity, (E) SQ Ox Phos content with representative Western blot images and (F) SQ AMPK and phosphorylated AMPK at Serine 485 and Threonine residues with representative Western blot images. AMPK, 5'AMP-activated protein kinase; EPI, epididymal (visceral); EX, exercise; FGF21KO, FGF21 knockout; Ox Phos, mitochondrial oxidative phosphorylation subunit complexes; SED, sedentary; SQ, subcutaneous (inguinal); WT, wild-type. *Significant genotype main effect $(P \leq 0.05)$; 'Significant exercise main effect $(P \leq 0.05)$; aSignificantly different compared to all other groups based on significant genotype $\times$ exercise effect followed by post hoc Tukey's tests $(P \leq 0.05)$; bSignificantly different than WT-SED based on significant genotype $\times$ exercise effect followed by post hoc Tukey's tests $(P \leq 0.05)(P \leq 0.05)$; csignificantly different than FGF21KO-EX based on significant genotype $\times$ exercise effect followed by post hoc Tukey's tests $(P \leq 0.05)$. 
A
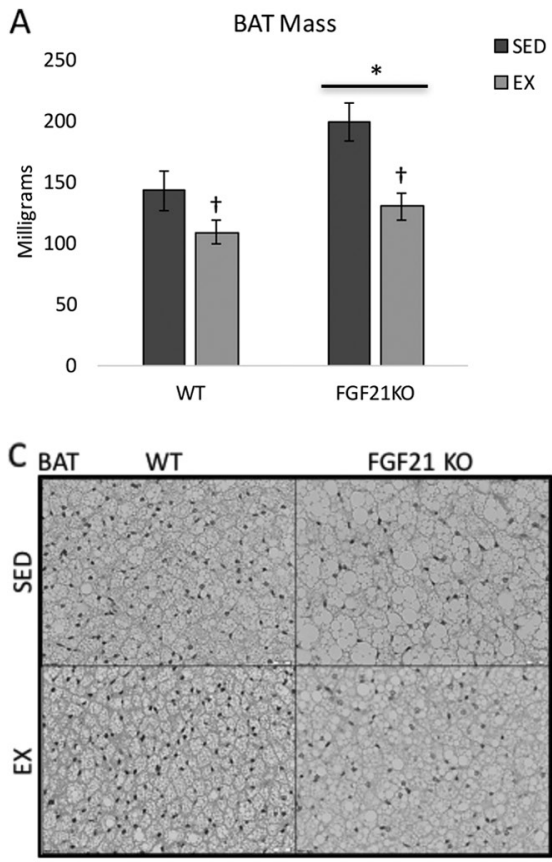

B
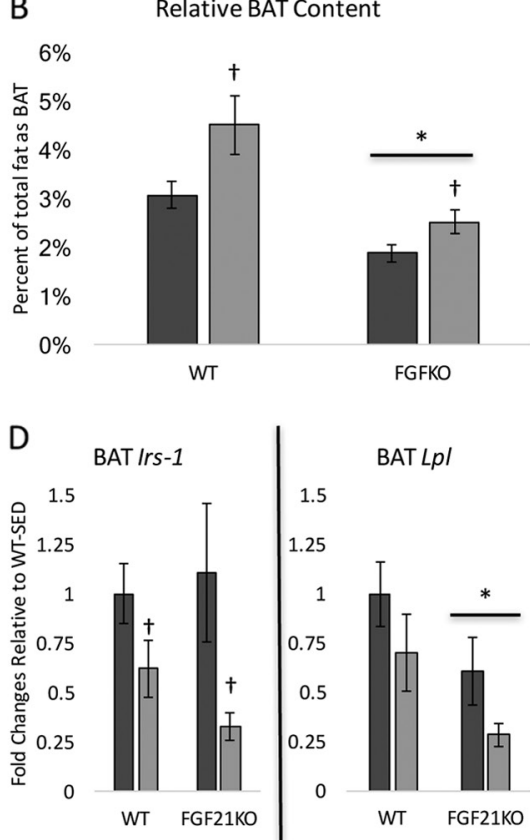

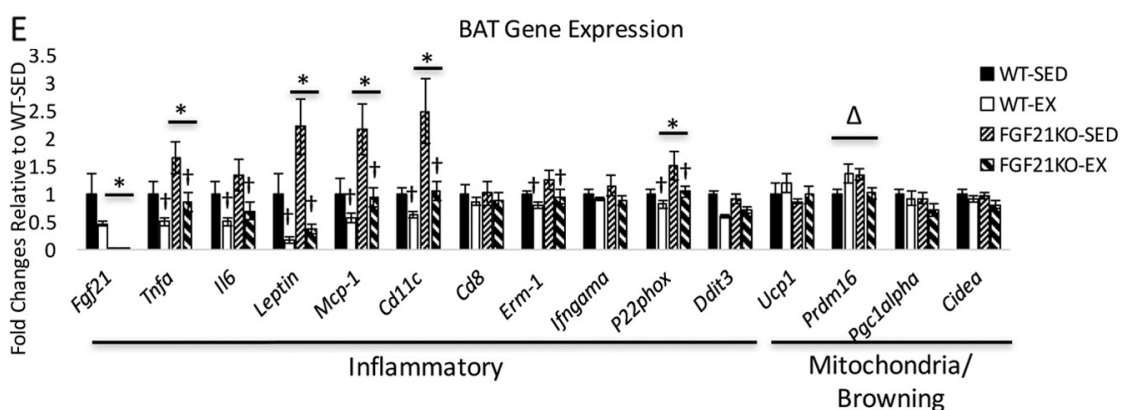

\section{Figure 5}

Influence of FGF21 ablation and/or exercise on BAT characteristics and gene expression. (A) BAT mass, (B) Relative BAT Content (BAT weight/(Body Mass $\times$ Body Fat Percentage) $) \times 100$,

(C) Representative Images of BAT H\&E staining, (D) BAT Irs1 and EPI Lp/ gene expression, and (E) BAT gene expression. BAT, brown adipose tissue; EX, exercise; FGF21KO, FGF21 knockout; SED, sedentary; WT, wild-type. Values are means \pm S.E. $\triangle$ Significant genotype by exercise interaction main effect $(P \leq 0.05)$; *Significant genotype main effect $(P \leq 0.05)$; 'Significant exercise main effect $(P \leq 0.05)$. normalized with EX (Fig. 5E). It should be noted that BAT adaptive thermogenic activity was not directly assessed. Taken together, these results indicate that loss of FGF21 increases BAT and WAT inflammation, and may adversely affect normal mitochondrial adaptations to exercise. Additionally, the present data do not support exercisemediated browning of WAT in mice following 8 weeks of voluntary wheel running.

\section{Discussion}

FGF21 is an endocrine hormone that is mainly produced in the liver, but is expressed in several tissues including skeletal muscle, pancreas and AT (Perez-Marti et al. 2016). While the mechanism(s) behind FGF21's potent insulinsensitizing effects are not completely understood, its specific actions are thought to be key in predicting its systemic benefits (Adams et al. 2012, Gomez-Hernandez et al. 2016, Samms et al. 2016). Exercise training has strikingly similar actions, profoundly affecting AT by reducing inflammation and improving mitochondrial metabolism (i.e., improving 'immunometabolism') (Thompson et al. 2012, Vieira-Potter et al. 2015), yet the mechanisms are not well understood. Intriguingly, a vast majority of studies demonstrate changes in circulating FGF21 levels with exercise. However, the inconsistencies in the magnitude and direction of change make it difficult to define the extent to which FGF21 may contribute to the metabolic adaptations associated with exercise. Although acute exercise increased circulating and skeletal muscle FGF21 levels in some studies (Kim et al. 2013, Slusher et al. 2015, Hansen et al. 2016, Tanimura et al. 2016), it induced no change or a reduction in circulating FGF21 in others (Taniguchi et al. 2016).

Thus, its role in exercise-mediated browning of WAT (Stanford et al. 2015), a process associated with both reduced inflammation (Liu et al. 2015) and increased mitochondrial function (Bae et al. 2014), requires further investigation. Here, we tested whether FGF21 is required

Published by Bioscientifica Ltd 
A

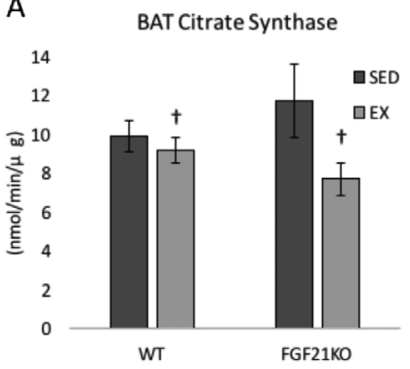

\section{B}

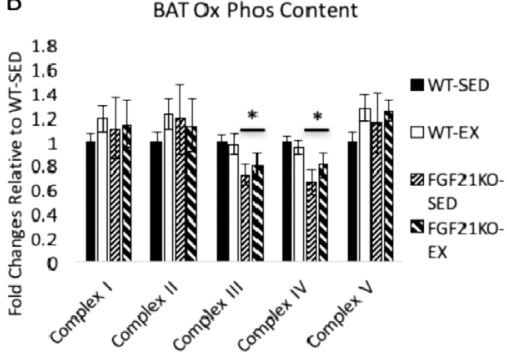

C BATOXPhos WT- FGF21KO WT- FGF21KO

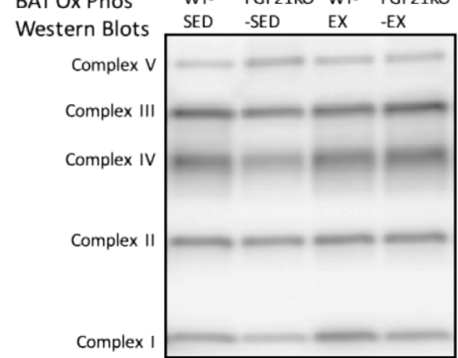

D

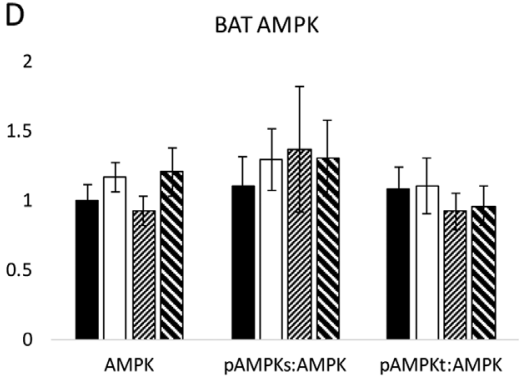

E

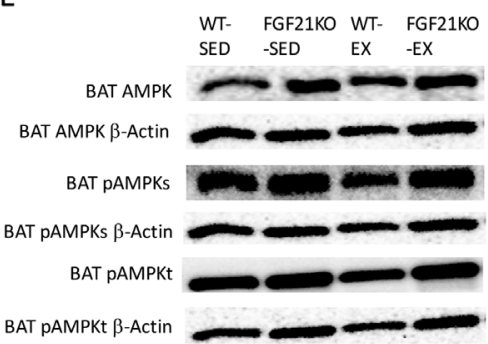

\section{Figure 6}

Influence of FGF21 ablation and/or exercise on BAT mitochondrial content and activity. (A) Citrate synthase activity, (B) Ox Phos Content, (C) Western blot images of Ox Phos complexes, (D) Total AMPK and phosphorylated AMPK at Serine 485 and Threonine 172 residues relative to total AMPK, and (E) Western blot images of AMPK and phosphorylated subunits. AMPK, 5'AMP-activated protein kinase; BAT, brown adipose tissue; EX, exercise; FGF21KO, FGF21 knockout; Ox Phos, mitochondrial oxidative phosphorylation subunit complexes; SED, sedentary; WT, wild-type. Values are means \pm s.E.

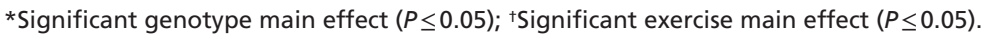

for exercise-mediated immunometabolic adaptations in AT. To this end, we used FGF21KO mice to determine if FGF21 is necessary for the immunometabolic adaptations due to exercise training in WAT and/or BAT, demonstrating for the first time that absence of FGF21 under normal dietary conditions leads to a dysfunctional AT phenotype characterized by inflammation and impaired mitochondrial oxidative metabolism. Importantly, this unhealthy phenotype was largely rescued with exercise training, indicating that FGF21 is dispensable for exerciseinduced anti-inflammatory effects in AT.

In agreement with previous studies (Badman et al. 2009, Laeger et al. 2014), we found that FGF21KO mice have increased adiposity, which is accompanied by an overall impaired metabolic profile. Although energy expenditure was not directly assessed, FGF21KO animals consumed more energy, suggesting that their greater adiposity was at least partially due to hyperphagia. Voluntary wheel running reduced all measures of adiposity in both WT and FGF21KO animals, and FGF21KO were no less responsive to those adiposity-reducing effects. Recently, Loyd and coworkers exposed FGF21KO mice to chronic high-fat feeding and voluntary wheel running, and also demonstrated that the effects of exercise on body weight and adiposity occur independent of FGF21
(Loyd et al. 2016). Increased adiposity and adipocyte size in the FGF21KO-SED group were associated with a higher Adipo-IR value, a surrogate index of AT insulin resistance (Lomonaco et al. 2012). Consistently, expression of proinflammatory and endoplasmic reticulum (ER) stress markers was increased in visceral WAT from FGF21KO-SED mice. Reduced Adipo-IR, which associated with increased Irs1 expression and decreased inflammatory/ER stress gene expression in WAT, regardless of genotype, further demonstrating that exercise's ability to improve WAT phenotype does not require FGF21.

Exercise-associated reductions in WAT inflammation have been previously reported; however, the majority of these studies were performed in obese animals (Bradley et al. 2008, Vieira et al. 2009a, Welly et al. 2016). Here, we demonstrate that the anti-inflammatory effects of exercise also occur in WAT and BAT of otherwise healthy, but previously sedentary, chow-fed mice. While FGF21KO-SED WAT and BAT had a more pro-inflammatory phenotype compared to WT-SED mice, it is unclear if that was a direct effect of FGF21 ablation or secondary to the increase in adiposity observed in the $\mathrm{KO}$ mice. However, emerging data suggest a direct role for FGF21 in alleviating ER stress and inflammation (Wang et al. 2014, Guo et al. 2016, Yu et al. 2016). In order to interrogate further whether the

Published by Bioscientifica Ltd 
inflammatory changes observed in the $\mathrm{KO}$ mice were dependent or independent of the increase in adiposity, we statistically adjusted for the effect of body weight on all inflammatory outcomes (Supplementary Table 1, see section on supplementary data given at the end of this article). We found that many, yet not all, of the differences in inflammatory genes were no longer significantly elevated in the KO compared to WT mice, suggesting that the elevated adiposity in the KO contributed significantly to their greater WAT and BAT inflammation. However, even after this statistical adjustment, KO maintained greater levels of visceral WAT $C d 8$ (an inflammatory T cell marker associated with insulin resistance (Nishimura et al. 2009) gene expression and tended to $(P=0.053)$ maintain greater $T n f a$ (an inflammatory cytokine known to secreted by inflammatory macrophages and impair adipocyte insulin signaling (Hotamisligil et al. 1996)) levels; these findings support that the absence of FGF21 does have adverse inflammatory effects on AT independent of body weight. While it is likely that the effect of exercise to reduce AT inflammation was at least somewhat driven by its ability to reduce adiposity, even after the body weight adjustment, exercise-mediated reductions in WAT and BAT Leptin gene expression remained statistically significant, as did the exercise-mediated reduction in WAT macrophage gene expression (i.e., Erm-1), confirming previous reports of exercise having direct anti-inflammatory effects in AT (Castellani et al. 2014, Peppler et al. 2017).

Accumulating evidence supports important relationships between mitochondrial and immune function suggesting that impaired mitochondrial health associates with greater inflammation (Vamecq et al. 2012, Qatanani et al. 2013, Hahn et al. 2014). Although lean AT is characterized by the absence of inflammation and increased mitochondrial function (Flachs et al. 2013), obese/sedentary AT is typified by a pro-inflammatory phenotype and impaired mitochondrial activity (Okamoto et al. 2007). Meanwhile, exercise improves WAT mitochondrial content and function (Wang et al. 2014, Stanford et al. 2015) and reports have implicated FGF21 in mediating mitochondrial biogenesis via regulation of Pgc1alpha (Okamoto et al. 2007, Stanford et al. 2015). Thus, mitochondria-related markers were assessed in WAT and BAT to determine the potential impact of loss of FGF21 on the ability of exercise to affect these parameters. Consistent with our previous observation that hepatic mitochondrial function is impaired in FGF21KO mice and almost completely restored by exercise training (Fletcher et al. 2016), our current findings revealed important roles of both FGF21 and exercise in mediating AT mitochondrial adaptations.

In the absence of FGF21, BAT took on a phenotype more similar to WAT, including increased inflammation (e.g., increased Tnfa, Mcp-1, P22phox and Cd11c gene expression) and greater lipid deposition. Exercise decreased that inflammatory profile in both WT and KO mice. However, adjusting for total body weight caused most of those inflammatory improvements to lose statistical significance (Supplementary Table 1). Importantly, AT inflammation is known to adversely affect adipocyte insulin signaling, which contributes to systemic insulin resistance. While most work on inflammation-induced insulin resistance has been done on WAT, BAT is also insulin sensitive and its presence contributes to systemic protection against insulin resistance (Townsend \& Tseng 2012). Thus, BAT inflammation may adversely affect brown adipocyte insulin sensitivity and contribute to systemic insulin resistance, whereas FGF21 and exercise may both improve systemic insulin sensitivity by mitigating inflammation in WAT and BAT. Indeed, we found that exercise reduced BAT Tnfa and Irs1 gene expression, whereas Tnfo is known to cause adipocyte insulin resistance via its inhibitory actions on Irs1 (Hotamisligil et al. 1996). In terms of BAT mitochondrial assessments, KO had significantly lower mitochondrial oxidative phosphorylation complexes III and IV (i.e., COXIII, IV protein content). Although the main effect of genotype on COXIII was not statistically significant following body weight adjustment, the suppressed BAT COXIV in KO remained even after this adjustment, suggesting a direct protective role of FGF21.

In conclusion, absence of FGF21 results in increased adiposity, AT insulin resistance and inflammation in both WAT and BAT. Importantly, exercise largely normalized the dysfunctional AT phenotype in FGF21KO animals. These new findings reveal the importance of FGF21 in maintaining a healthy AT phenotype under sedentary conditions, while revoking the hypothesis that the antiinflammatory effects of exercise in AT require FGF21.

\section{Supplementary data}

This is linked to the online version of the paper at http://dx.doi.org/10.1530/ JOE-17-0190.

\section{Declaration of interest}

J W Perfield II is a paid employee of Eli Lilly and Company and may own company stock or possess stock options. The remaining authors have no conflicts of interest to disclose.
Published by Bioscientifica Ltd 


\section{Funding}

The project described was supported by grants from ACSM Foundations Research Grant (J A F), NIH T32 AR 048523-07 (J A F), NIH DK088940 (J P T) and R25GM056901 from the National Institute of General Medical Science (NIGMS), a component of the National Institutes of Health (NIH), VA-Merit 101BX003271-01 (R S R), VA-Merit 101 RX000123 (J P T), MU Corporate Advisory Board (Porter), MU Research Board (V V P), MU Research Council (V V P) and NIH K01HL125503 (J P). Thanks to Grace Meers, Michelle Gastecki and Rebecca Welly for technical assistance with the animals and collection of samples. This work was supported with resources and the use of facilities at the Harry S. Truman Memorial VA Hospital in Columbia, MO.

\section{References}

Adams AC, Yang C, Coskun T, Cheng CC, Gimeno RE, Luo Y \& Kharitonenkov A 2012 The breadth of FGF21's metabolic actions are governed by FGFR1 in adipose tissue. Molecular Metabolism 2 31-37. (doi:10.1016/j.molmet.2012.08.007)

Badman MK, Koester A, Flier JS, Kharitonenkov A \& Maratos-Flier E 2009 Fibroblast growth factor 21-deficient mice demonstrate impaired adaptation to ketosis. Endocrinology 150 4931-4940. (doi:10.1210/ en.2009-0532)

Bae KH, Kim JG \& Park KG 2014 Transcriptional regulation of fibroblast growth factor 21 expression. Endocrinology and Metabolism 29 105-111. (doi:10.3803/EnM.2014.29.2.105)

Bradley RL, Jeon JY, Liu FF \& Maratos-Flier E 2008 Voluntary exercise improves insulin sensitivity and adipose tissue inflammation in dietinduced obese mice. American Journal of Physiology: Endocrinology and Metabolism 295 E586-E594. (doi:10.1152/ajpendo.00309.2007)

Castellani L, Root-Mccaig J, Frendo-Cumbo S, Beaudoin MS \& Wright DC 2014 Exercise training protects against an acute inflammatory insult in mouse epididymal adipose tissue. Journal of Applied Physiology 116 1272-1280. (doi:10.1152/japplphysiol.00074.2014)

Crissey JM, Jenkins NT, Lansford KA, Thorne PK, Bayless DS, Vieira-Potter VJ, Rector RS, Thyfault JP, Laughlin MH \& Padilla J 2014 Adipose tissue and vascular phenotypic modulation by voluntary physical activity and dietary restriction in obese insulin-resistant OLETF rats. American Journal of Physiology: Regulatory, Integrative and Comparative Physiology 306 R596-R606. (doi:10.1152/ajpregu.00493.2013)

Feingold KR, Grunfeld C, Heuer JG, Gupta A, Cramer M, Zhang T, Shigenaga JK, Patzek SM, Chan ZW, Moser A, et al. 2012 FGF21 is increased by inflammatory stimuli and protects leptin-deficient ob/ ob mice from the toxicity of sepsis. Endocrinology 153 2689-2700. (doi:10.1210/en.2011-1496)

Flachs P, Rossmeisl M, Kuda O \& Kopecky J 2013 Stimulation of mitochondrial oxidative capacity in white fat independent of UCP1: a key to lean phenotype. Biochimica et Biophysica Acta 1831 986-1003. (doi:10.1016/j.bbalip.2013.02.003)

Fletcher JA, Linden MA, Sheldon RD, Meers GM, Morris EM, Butterfield A, Perfield JW 2nd, Thyfault JP \& Rector RS 2016 Fibroblast growth factor 21 and exercise-induced hepatic mitochondrial adaptations. American Journal of Physiology: Gastrointestinal and Liver Physiology $\mathbf{3 1 0}$ G832-G843. (doi:10.1152/ajpgi.00355.2015)

Gomez-Hernandez A, Beneit N, Diaz-Castroverde S \& Escribano O 2016 Differential role of adipose tissues in obesity and related metabolic and vascular complications. International Journal of Endocrinology 2016.

Guo Q, Xu L, Liu J, Li H, Sun H, Wu S \& Zhou B 2016 Fibroblast growth factor 21 reverses suppression of adiponectin expression via inhibiting endoplasmic reticulum stress in adipose tissue of obese mice. Experimental Biology and Medicine.

Hahn WS, Kuzmicic J, Burrill JS, Donoghue MA, Foncea R, Jensen MD, Lavandero S, Arriaga EA \& Bernlohr DA 2014 Proinflammatory cytokines differentially regulate adipocyte mitochondrial metabolism, oxidative stress, and dynamics. American Journal of Physiology: Endocrinology and Metabolism 306 E1033-E1045. (doi:10.1152/ajpendo.00422.2013)

Hansen JS, Pedersen BK, Xu G, Lehmann R, Weigert C \& Plomgaard P 2016 Exercise-induced secretion of FGF21 and follistatin are blocked by pancreatic clamp and impaired in type 2 diabetes. Journal of Clinical Endocrinology and Metabolism 101 2816-2825. (doi:10.1210/jc.2016-1681) Hotamisligil GS, Peraldi P, Budavari A, Ellis R, White MF \& Spiegelman BM 1996 IRS-1-mediated inhibition of insulin receptor tyrosine kinase activity in TNF-alpha- and obesity-induced insulin resistance. Science 271 665-668. (doi:10.1126/science.271.5249.665)

Iglesias P, Selgas R, Romero S \& Diez JJ 2012 Biological role, clinical significance, and therapeutic possibilities of the recently discovered metabolic hormone fibroblastic growth factor 21. European Journal of Endocrinology 167 301-309. (doi:10.1530/EJE-12-0357)

Ji K, Zheng J, Lv J, Xu J, Ji X, Luo YB, Li W, Zhao Y \& Yan C 2015 Skeletal muscle increases FGF21 expression in mitochondrial disorders to compensate for energy metabolic insufficiency by activating the mTOR-YY1-PGC1alpha pathway. Free Radical Biology and Medicine $\mathbf{8 4}$ 161-170. (doi:10.1016/j.freeradbiomed.2015.03.020)

Kharitonenkov A \& Shanafelt AB 2008 Fibroblast growth factor-21 as a therapeutic agent for metabolic diseases. BioDrugs 22 37-44. (doi:10.2165/00063030-200822010-00004)

Kharitonenkov A, Shiyanova TL, Koester A, Ford AM, Micanovic R, Galbreath EJ, Sandusky GE, Hammond LJ, Moyers JS, Owens RA, et al. 2005 FGF-21 as a novel metabolic regulator. Journal of Clinical Investigation 115 1627-1635. (doi:10.1172/JCI23606)

Kim KH \& Lee MS 2014 FGF21 as a stress hormone: the roles of FGF21 in stress adaptation and the treatment of metabolic diseases. Diabetes and Metabolism Journal 38 245-251. (doi:10.4093/dmj.2014.38.4.245)

Kim KH, Kim SH, Min YK, Yang HM, Lee JB \& Lee MS 2013 Acute exercise induces FGF21 expression in mice and in healthy humans. PLOS ONE 8 e63517. (doi:10.1371/journal.pone.0063517)

Laeger T, Henagan TM, Albarado DC, Redman LM, Bray GA, Noland RC, Munzberg H, Hutson SM, Gettys TW, Schwartz MW, et al. 2014 FGF21 is an endocrine signal of protein restriction. Journal of Clinical Investigation 124 3913-3922. (doi:10.1172/JCI74915)

Lee P, Linderman JD, Smith S, Brychta RJ, Wang J, Idelson C, Perron RM, Werner CD, Phan GQ, Kammula US, et al. 2014 Irisin and FGF21 are cold-induced endocrine activators of brown fat function in humans. Cell Metabolism 19 302-309. (doi:10.1016/j.cmet.2013.12.017)

Linden MA, Pincu Y, Martin SA, Woods JA \& Baynard T 2014 Moderate exercise training provides modest protection against adipose tissue inflammatory gene expression in response to high-fat feeding. Physiological Reports 2 e12071. (doi:10.14814/phy2.12071)

Liu PS, Lin YW, Burton FH \& Wei LN 2015 M1-M2 balancing act in white adipose tissue browning - a new role for RIP140. Adipocyte 4 146-148. (doi:10.4161/21623945.2014.981428)

Lomonaco R, Ortiz-Lopez C, Orsak B, Webb A, Hardies J, Darland C, Finch J, Gastaldelli A, Harrison S, Tio F, et al. 2012 Effect of adipose tissue insulin resistance on metabolic parameters and liver histology in obese patients with nonalcoholic fatty liver disease. Hepatology $\mathbf{5 5}$ 1389-1397. (doi:10.1002/hep.25539)

Loyd C, Magrisso IJ, Haas M, Balusu S, Krishna R, Itoh N, Sandoval DA, Perez-Tilve D, Obici S \& Habegger KM 2016 Fibroblast growth factor 21 is required for beneficial effects of exercise during chronic high-fat feeding. Journal of Applied Physiology 121 687-698. (doi:10.1152/ japplphysiol.00456.2016)

Matthews DR, Hosker JP, Rudenski AS, Naylor BA, Treacher DF \& Turner RC 1985 Homeostasis model assessment: insulin resistance and betacell function from fasting plasma glucose and insulin concentrations in man. Diabetologia 28 412-419. (doi:10.1007/BF00280883)

Nishimura S, Manabe I, Nagasaki M, Eto K, Yamashita H, Ohsugi M, Otsu M, Hara K, Ueki K, Sugiura S, et al. 2009 CD8+ effector T cells contribute to macrophage recruitment and adipose tissue inflammation in obesity. Nature Medicine 15 914-920. (doi:10.1038/nm.1964) http://joe.endocrinology-journals.org

DOI: $10.1530 / \mathrm{JOE}-17-0190$
๑ 2017 Society for Endocrinology Printed in Great Britain 
Okamoto Y, Higashiyama H, Rong JX, McVey MJ, Kinoshita M, Asano S \& Hansen MK 2007 Comparison of mitochondrial and macrophage content between subcutaneous and visceral fat in $\mathrm{db} / \mathrm{db}$ mice. Experimental and Molecular Pathology 83 73-83. (doi:10.1016/j.yexmp.2007.02.007)

Padilla J, Jenkins NT, Vieira-Potter VJ \& Laughlin MH 2013 Divergent phenotype of rat thoracic and abdominal perivascular adipose tissues. American Journal of Physiology: Regulatory, Integrative and Comparative Physiology 304 R543-R552. (doi:10.1152/ajpregu.00567.2012)

Peppler WT, Anderson ZG, MacRae LM, MacPherson REK \& Wright DC 2017 Habitual physical activity protects against lipopolysaccharideinduced inflammation in mouse adipose tissue. Adipocyte 6 1-11. (doi:10.1080/21623945.2016.1259778)

Perez-Marti A, Sandoval V, Marrero PF, Haro D \& Relat J 2016 Nutritional regulation of fibroblast growth factor 21: from macronutrients to bioactive dietary compounds. Hormone Molecular Biology and Clinical Investigation 30 article 34. (doi:10.1515/hmbci-2016-0034)

Qatanani M, Tan Y, Dobrin R, Greenawalt DM, Hu G, Zhao W, Olefsky JM, Sears DD, Kaplan LM \& Kemp DM 2013 Inverse regulation of inflammation and mitochondrial function in adipose tissue defines extreme insulin sensitivity in morbidly obese patients. Diabetes 62 855-863. (doi:10.2337/db12-0399)

Samms RJ, Smith DP, Cheng CC, Antonellis PP, Perfield JW 2nd, Kharitonenkov A, Gimeno RE \& Adams AC 2015 Discrete aspects of FGF21 in vivo pharmacology do not require UCP1. Cell Reports 11 991-999. (doi:10.1016/j.celrep.2015.04.046)

Samms RJ, Cheng CC, Kharitonenkov A, Gimeno RE \& Adams AC 2016 Overexpression of beta-Klotho in adipose tissue sensitizes male mice to endogenous FGF21 and provides protection from diet-induced obesity. Endocrinology 157 1467-1480. (doi:10.1210/en.2015-1722)

Schlein C, Talukdar S, Heine M, Fischer AW, Krott LM, Nilsson SK, Brenner MB, Heeren J \& Scheja L 2016 FGF21 lowers plasma triglycerides by accelerating lipoprotein catabolism in white and brown adipose tissues. Cell Metabolism 23 441-453. (doi:10.1016/j.cmet.2016.01.006)

Singhal G, Fisher FM, Chee MJ, Tan TG, El Ouaamari A, Adams AC, Najarian R, Kulkarni RN, Benoist C, Flier JS, et al. 2016 Fibroblast growth factor 21 (FGF21) protects against high fat diet induced inflammation and islet hyperplasia in pancreas. PLOS ONE $\mathbf{1 1}$ e0148252. (doi:10.1371/journal.pone.0148252)

Slusher AL, Whitehurst M, Zoeller RF, Mock JT, Maharaj M \& Huang CJ 2015 Attenuated fibroblast growth factor 21 response to acute aerobic exercise in obese individuals. Nutrition, Metabolism and Cardiovascular Diseases 25 839-845. (doi:10.1016/j.numecd.2015.06.002)

Stallknecht B, Vinten J, Ploug T \& Galbo H 1991 Increased activities of mitochondrial enzymes in white adipose tissue in trained rats. American Journal of Physiology 261 E410-E414.

Stanford KI \& Goodyear LJ 2016 Exercise regulation of adipose tissue. Adipocyte 5 153-162. (doi:10.1080/21623945.2016.1191307)

Stanford KI, Middelbeek RJ \& Goodyear LJ 2015 Exercise effects on white adipose tissue: beiging and metabolic adaptations. Diabetes 64 2361-2368. (doi:10.2337/db15-0227)

Sun Y, Qi Z, He Q, Cui D, Qian S, Ji L \& Ding S 2015 The effect of treadmill training and $\mathrm{N}$-acetyl-1-cysteine intervention on biogenesis of cytochrome c oxidase (COX). Free Radical Biology and Medicine $\mathbf{8 7}$ 326-335. (doi:10.1016/j.freeradbiomed.2015.06.035)

Taniguchi H, Tanisawa K, Sun X \& Higuchi M 2016 Acute endurance exercise lowers serum fibroblast growth factor 21 levels in Japanese men. Clinical Endocrinology 85 861-867. (doi:10.1111/cen.13162)
Tanimura Y, Aoi W, Takanami Y, Kawai Y, Mizushima K, Naito Y \& Yoshikawa T 2016 Acute exercise increases fibroblast growth factor 21 in metabolic organs and circulation. Physiological Reports 4 e12828. (doi:10.14814/phy2.12828)

Thompson D, Karpe F, Lafontan M \& Frayn K 2012 Physical activity and exercise in the regulation of human adipose tissue physiology. Physiological Reviews 92 157-191. (doi:10.1152/physrev.00012.2011)

Townsend K \& Tseng Y-H 2012 Brown adipose tissue: recent insights into development, metabolic function and therapeutic potential. Adipocyte 1 13-24. (doi:10.4161/adip.18951)

Vamecq J, Dessein AF, Fontaine M, Briand G, Porchet N, Latruffe N, Andreolotti P \& Cherkaoui-Malki M 2012 Mitochondrial dysfunction and lipid homeostasis. Current Drug Metabolism 13 1388-1400. (doi:10.2174/138920012803762792)

Vieira VJ, Valentine RJ, Wilund KR, Antao N, Baynard T \& Woods JA $2009 a$ Effects of exercise and low-fat diet on adipose tissue inflammation and metabolic complications in obese mice. American Journal of Physiology: Endocrinology and Metabolism 296 E1164-E1171. (doi:10.1152/ajpendo.00054.2009)

Vieira VJ, Valentine RJ, Wilund KR \& Woods JA $2009 b$ Effects of diet and exercise on metabolic disturbances in high-fat diet-fed mice. Cytokine 46 339-345. (doi:10.1016/j.cyto.2009.03.006)

Vieira-Potter VJ, Zidon TM \& Padilla J 2015 Exercise and estrogen make fat cells 'fit'. Exercise and Sport Sciences Reviews 43 172-178. (doi:10.1249/JES.0000000000000046)

Wainright KS, Fleming NJ, Rowles JL, Welly RJ, Zidon TM, Park YM, Gaines TL, Scroggins RJ, Anderson-Baucum EK, Hasty AM, et al. 2015 Retention of sedentary obese visceral white adipose tissue phenotype with intermittent physical activity despite reduced adiposity. American Journal of Physiology: Regulatory, Integrative and Comparative Physiology 309 R594-R602. (doi:10.1152/ajpregu.00042.2015)

Wang XM, Song SS, Xiao H, Gao P, Li XJ \& Si LY 2014 Fibroblast growth factor 21 protects against high glucose induced cellular damage and dysfunction of endothelial nitric-oxide synthase in endothelial cells. Cellular Physiology and Biochemistry 34 658-671. (doi:10.1159/000363031)

Welly RJ, Liu TW, Zidon TM, Rowles JL 3rd, Park YM, Smith TN, Swanson KS, Padilla J \& Vieira-Potter VJ 2016 Comparison of diet vs. exercise on metabolic function \& gut microbiota in obese rats. Medicine and Science in Sports and Exercise 48 1688-1698. (doi:10.1249/ MSS.0000000000000964)

Xu X, Ying Z, Cai M, Xu Z, Li Y, Jiang SY, Tzan K, Wang A, Parthasarathy S, He G, et al. 2011 Exercise ameliorates high-fat dietinduced metabolic and vascular dysfunction, and increases adipocyte progenitor cell population in brown adipose tissue. American journal of Physiology: Regulatory, Integrative and Comparative Physiology 300 R1115-R1125. (doi:10.1152/ajpregu.00806.2010)

Yu Y, He J, Li S, Song L, Guo X, Yao W, Zou D, Gao X, Liu Y, Bai F, et al. 2016 Fibroblast growth factor 21 (FGF21) inhibits macrophagemediated inflammation by activating Nrf2 and suppressing the NF-kappaB signaling pathway. International Immunopharmacology $\mathbf{3 8}$ 144-152. (doi:10.1016/j.intimp.2016.05.026)

Zhang X, Yeung DC, Karpisek M, Stejskal D, Zhou ZG, Liu F, Wong RL, Chow WS, Tso AW, Lam KS, et al. 2008 Serum FGF21 levels are increased in obesity and are independently associated with the metabolic syndrome in humans. Diabetes 57 1246-1253. (doi:10.2337/db07-1476)

Received in final form 28 July 2017

Accepted 1 August 2017

Accepted Preprint published online 1 August 2017
๑) 2017 Society for Endocrinology Printed in Great Britain
Published by Bioscientifica Ltd. 